DOI: $10.1002 /($ please add manuscript number)

Article type: Communication

\title{
Finely Tuned Submicroporous Thin-Film Molecular Sieve Membranes for Highly Efficient Fluid Separations
}

\author{
Zain Ali, Bader S. Ghanem, Yingge Wang, Federico Pacheco, Wojciech Ogieglo, Hakkim \\ Vovusha, Giuseppe Genduso, Udo Schwingenschlögl, Yu Han and Ingo Pinnau*
}

Dr. Z. Ali, Dr. B. Ghanem, Dr. Y. Wang, Dr. F. Pacheco, Dr. W. Ogieglo, Dr. G. Genduso, Prof. Y. Han, Prof. I. Pinnau.

Advanced Membranes \& Porous Materials Center, Division of Physical Sciences and Engineering, King Abdullah University of Science and Technology, Thuwal 23955-6900, KSA. E-mail: ingo.pinnau@kaust.edu.sa

Dr. H. Vovusha, Prof. U. Schwingenschlögl.

Division of Physical Sciences and Engineering, King Abdullah University of Science and Technology, Thuwal 23955-6900, KSA.

Keywords: interfacial polymerization, triptycene acid chloride monomer, thin-film composite membrane, defect-free polyamide layer, submicropores

Polymeric membranes with increasingly high permselective performances are gaining a significant role in lowering the energy burden and improving the environmental sustainability of complex chemical separations. However, commercial deployment of newly designed materials with promising intrinsic properties for fluid separations has been stalled by challenges associated with fabrication and scale up of low-cost, high performance defect-free thin-film composite (TFC) membranes. Here, a facile method to fabricate the next generation TFC membranes using a bridged-bicyclic triptycene tetra-acyl chloride (Trip) building block with a large fraction of finely tuned structural submicroporosity (pore size $<4 \AA$ ) is demonstrated. The TFCs exhibit superb potential for removal of small $\left(\sim 200 \mathrm{~g} \mathrm{~mol}^{-1}\right)$ organic micro-contaminants from organic solvent streams by showing both improved rejection and permeance in organic systems compared to current state-of-the-art commercial membranes. The TFCs also display unprecedented properties for desalination applications with performance located far above the current water permeance/sodium chloride rejection trendline. The strategy of using highly 


\section{WILEY-VCH}

contorted triptycene building blocks with well-defined interconnected internal free volume elements establishes a scalable, generalized approach to fabricate highly selective, submicroporous TFC membranes for a wide variety of challenging energy-intensive fluid separations. 


\section{WILEY-VCH}

Current large-scale unit operation processes for fluid separations are primarily based on thermal principles and account for $\sim 10-15 \%$ of the world's total energy consumption. ${ }^{[1]}$ This massive energy penalty for purification of liquid and gaseous feed stocks provides a high impact opportunity for alternative processes. Membrane technology is emerging as one of the most promising energy efficient separation processes in the chemical separation industry. Its continued growth can be attributed to lower energy requirements translating to lower capital and operating cost as well as significantly reduced environmental impact compared to conventional thermal separation processes. Additionally, membrane technology offers the advantages of continuous process operation, modular design, and small system footprint and is predicted to be a main contributor to global energy- and carbon-reduction initiatives in the coming decades. ${ }^{[2]}$

In 2008 , the global membrane market was valued at $\sim 12$ billion USD with a compound annual growth rate (CAGR) of $\sim 10 \% .{ }^{[3]}$ Reverse osmosis (RO) and nanofiltration (NF) membranes contribute significantly to the total global membrane sales with the majority of products comprising of variations of thin-film composite (TFC) membranes made by interfacial polymerization. Such highly crosslinked aromatic submicroporous (i.e., pore size $<4 \AA)^{[4]}$ polyamide TFC membranes — pioneered by John Cadotte — revolutionized the desalination industry due to their unprecedented combination of high water flux and salt rejection. ${ }^{[5-8]}$ Surprisingly, despite their immense commercial success for aqueous RO and NF applications, the IP membrane formation process has not been implemented in other large-scale fluid separation processes, especially organic solvent nanofiltration (OSN) and gas separations. ${ }^{[9-11]}$ Polymers of intrinsic microporosity (PIMs) are an emerging group of solution processible amorphous microporous materials (pore size $<20 \AA$ ) gaining significant attention in membranebased separations due to their ability to transcend the conventional permeability/selectivity trade-off relationships. ${ }^{[12-15]}$ Such materials exhibit exceptionally high free volumes as a result of inefficient chain packing by architectural designs using highly rigid and contorted 


\section{WILEY-VCH}

spirobisindane-, triptycene-, ethanoanthracene-, and Tröger's base-building blocks. ${ }^{[13,16-21]}$ To date, technical challenges associated with fabricating defect-free, inexpensive, thin-film composite membranes as well as the inability to achieve low molecular weight cut-offs (MWCOs) have severely limited the industrial use of PIM-based and similar membrane materials. For example, Cook et al. demonstrated successful dip-coating of several ladder polymers (PIM-1, PIM-7, PIM-8) on crosslinked polyetherimide (Ultem 1000) and polyacrylonitrile porous supports with thicknesses of $\sim 100-300 \mathrm{~nm} \cdot{ }^{[22]}$ The membranes showed reasonable solvent permeances (PIM-1 displayed methanol permeance of 2.5 $\mathrm{LMH} /$ bar) but suffered from moderate solute rejections translating to high MWCOs in the range of 500-800 $\mathrm{g} \mathrm{mol}^{-1}$ for OSN applications. For small solutes such as $300 \mathrm{~g} \mathrm{~mol}^{-1}$ polystyrene, PIM-1 exhibited only a rejection of $<5 \%$ in methanol.

Thin-film fabrication using in-situ interfacial polymerization (IP) offers a promising alternative method to produce highly crosslinked, reproducible, ultrathin PIM-derived membranes employing an industrially scalable, low-cost, roll-to-roll process. ${ }^{[8,23-26]}$ Early reports demonstrated that IP-based polyarylate TFCs can be sucessfully produced from PIM-motifs, e.g. spirobisindane-derived biscatechol sodium salts reacted with trimesoylchloride (TMC) proposed for use in OSN. ${ }^{[27]}$ Similar to the work reported for dip-coated ladder PIMs ${ }^{[22]}$, the resulting membranes demonstrated high organic solvent permeances due to their microporous texture but exhibited only moderate organic solute rejections (i.e., moderate solute cut-off), thereby limiting their potential for commercial OSN applications. Interestingly, water permeance and salt rejection properties of the polyarylate-based TFCs have not been reported to date.

Triptycene, a member of the iptycene family, has been established as a remarkable PIM building block for ladder PIMs and PIM-polyimides (PIM-PIs) as gas separation membrane materials owing to its rigid and 3D paddlewheel-like structure with uniformely structured internal fractional free volume (IFV), making it an excellent candidate monomer material to synthesize 


\section{WILEY-VCH}

TFCs by IP..$^{[16,28-34]}$ Ren et al. ${ }^{[33]}$ reported semi-aromatic co-polyamide membranes of triptycene hexaacyl chloride (TPA) and TMC reacted with piperazine (PIP) by interfacial polymerization for RO and OSN applications. An increase in the content of the triptycene moiety in the copolymer boosted water permeance but also resulted in unacceptable loss in salt and organic solute rejections. For example, a membrane made from 80\% TPA and 20\% TMC reacted with PIP (TPA-80) exhibited poor $\mathrm{NaCl}$ and $\mathrm{MgSO}_{4}$ rejections of 10.5 and $38.5 \%$, respectively.

(a)
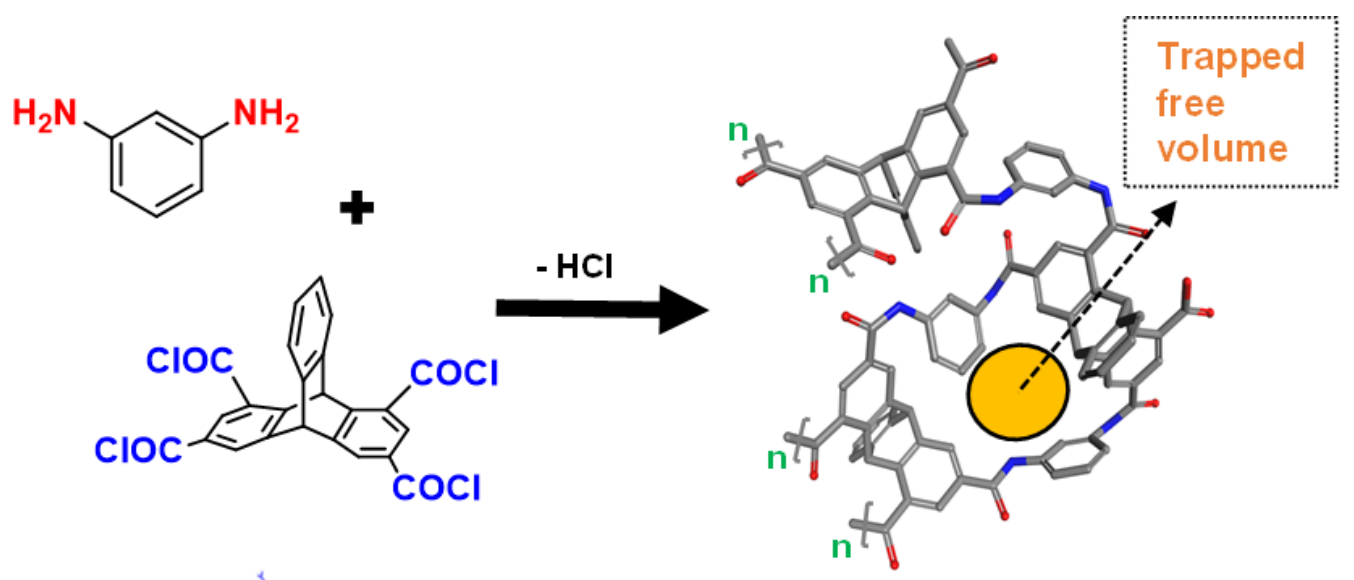

(b)

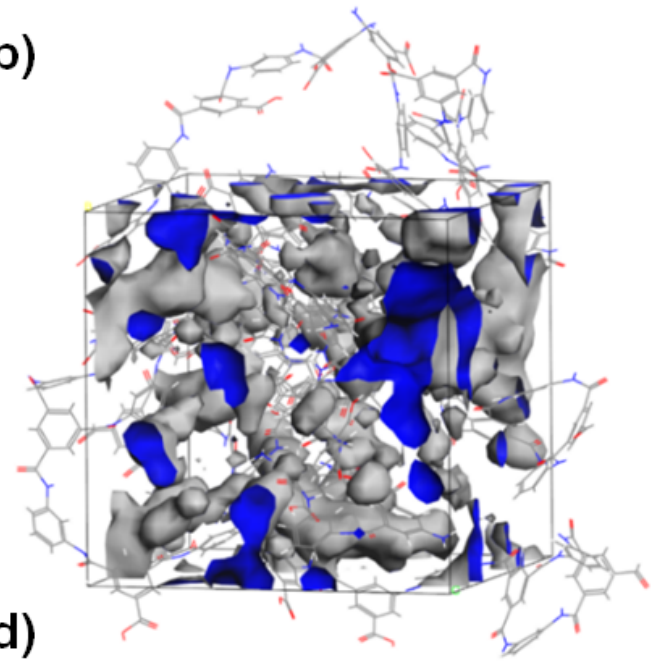

(d)

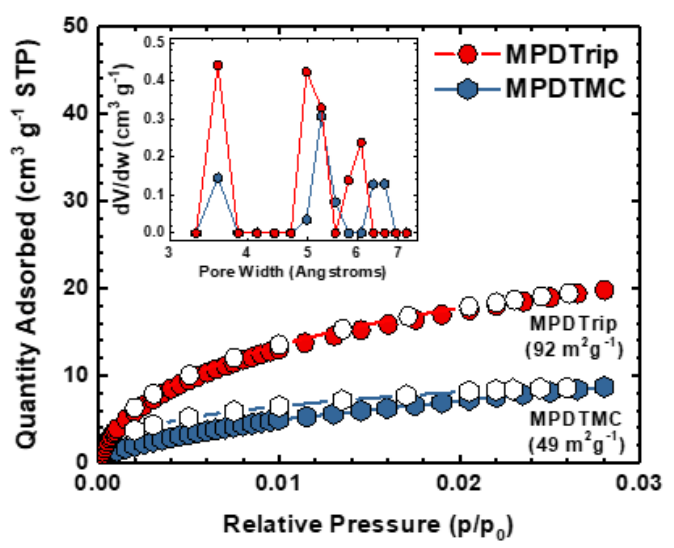

(c)

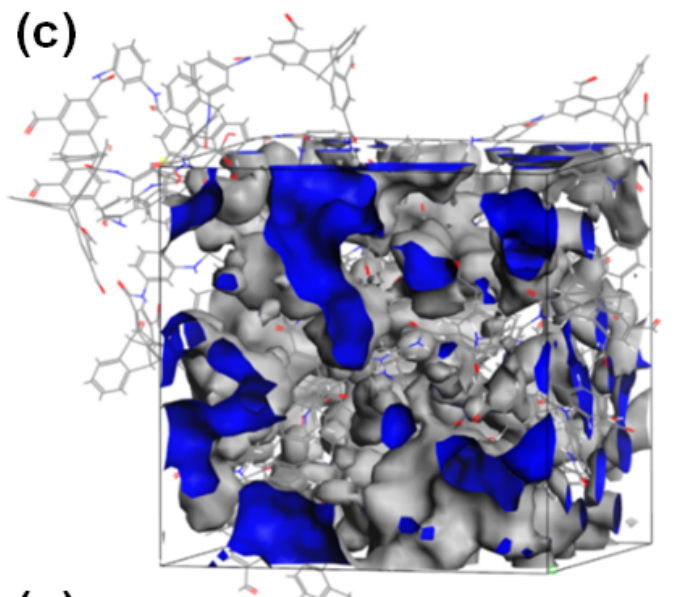

(e)

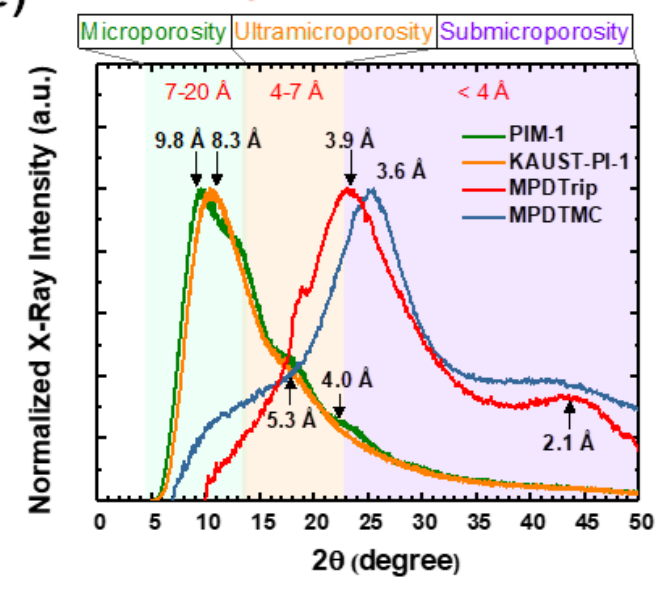




\section{WILEY-VCH}

Figure 1. Characterization of interfacially polymerized polymers. (a) Reaction scheme for the synthesis of crosslinked aromatic polyamide using MPD and triptycene-1,3,6,8-tetraacetyl chloride (Trip) monomers with internal free volume (IFV) trapped within chain repeat units, (b) MPDTMC and, (c) MPDTrip energy-minimized amorphous cells. The Connolly surface area of MPDTMC is estimated as $1900 \AA^{2}$ and that of MPDTrip as $4700 \AA^{2}$ with MPDTrip exhibiting improved IFV interconnectivity. Grey/blue isosurfaces represent the accessible free volume at a probe radius of $1 \AA$, (d) sorption behavior using $\mathrm{CO}_{2} \mathrm{BET}$ measurements at $273 \mathrm{~K}$ up to $1 \mathrm{bar}$ for MPDTMC and MPDTrip powders. Inset denotes pore size distributions for MPDTMC and MPDTrip powders obtained from $\mathrm{CO}_{2}$ isotherms at $273 \mathrm{~K}$ employing the nonlocal density functional theory (NLDFT), (e) XRD spectra of MPDTMC and MPDTrip powders with average d-spacing obtained using Bragg's law.

Herein, we report the successful fabrication of highly permeable and selective interfacially polymerized fully aromatic polyamide thin-film composite membranes using a novel bridgedbicyclic triptycene-based tetra-acyl chloride (Trip) PIM-type building block with $m$-phenylene diamine (MPD). The TFC membranes showed exceptional performance with potential for a wide range of energy intensive fluid separations, including brackish water RO, organic NF and $\mathrm{H}_{2} / \mathrm{CO}_{2}$ gas separation. The superb performance of the newly developed membranes resulted from the dominant fraction of finely tuned submicropores (average pores $<4 \AA$ ) in the selective, strongly hydrogen-bonded polyamide layer.

Figure 1a shows the reaction scheme of the triptycene-1,3,6,8-tetraacetyl chloride (Trip) monomer with MPD to fabricate a fully aromatic, highly crosslinked network polyamide (polyaramid). The 3D structure of the triptycene moiety, comprising of a [2,2,2]-tricyclic ring system with three benzene groups fused at $120^{\circ}$, entraps permanent intramolecular free volume (IFV) when compared to the traditional commercially used planar trimesoyl chloride moiety. Molecular dynamics simulations (Figure 1b and 1c) demonstrated that the substitution of the TMC with the sterically hindered triptycene moiety permitted a significant increase of the polymer fractional free volume (from $\sim 14$ to $24 \%$ ) and higher interconnectivity between the free volume units. Accessible surface area and pore size distributions of MPDTMC and MPDTrip polymer powders were probed using $\mathrm{CO}_{2}$ sorption at $273 \mathrm{~K}$ which displayed about two-fold increase in accessible surface area (from 49 to $92 \mathrm{~m}^{2} \mathrm{~g}^{-1}$ ) for MPDTrip (Figure 1d) while maintaining a dominant fraction of submicropores (Figure S6a-b). Isosteric heat of 


\section{WILEY-VCH}

adsorption (Figure S6d) displayed minimal variation (approximately between 30-40 kJ mol${ }^{-1}$ ) between the two systems. This confirmed the improvement of the accessible surface area in MPDTrip resulted from the geometry of the triptycene building block rather than its improved interaction with the acidic and quadrupolar $\mathrm{CO}_{2}$ gas. ${ }^{[35,36]}$ However, it is important to note that the accessible surface areas obtained here using both bulk network polyamides were significantly lower than the surface areas of linear and network PIMs previously reported. ${ }^{[15,37]}$ Classical polymers of intrinsic microporosity with BET surface areas (calculated using $\mathrm{N}_{2}$ sorption isotherms) of $\sim 800 \mathrm{~m}^{2} \mathrm{~g}^{-1}$, such as PIM-1 and KAUST-PI-1, contain a bimodal pore size distribution containing a large fraction of micropores $(\sim 7-20 \AA)$ with embedded ultramicropores $(<7 \AA) .{ }^{[38]}$ Here, both materials displayed BET surface areas of $<50 \mathrm{~m}^{2} \mathrm{~g}^{-1}$ obtained from $\mathrm{N}_{2}$ adsorption isotherms at $77 \mathrm{~K}$ (Figures S7). Figure 1e compares the XRD spectra of these two highly microporous PIMs with MPDTRIP and MPDTMC — both MPDbased polymers show an amorphous structure as indicated by their broad diffraction spectra. Furthermore, the average chain d-spacing (calculated by Bragg's law) indicates submicroporous structural characteristics for both MPDTrip $(\mathrm{d}=3.90 \AA)$ and MPDTMC $(\mathrm{d}=$ 3.6 ̊), whereas traditional microporous polymers, PIM-1 and KAUST-PI-1, display main dspacings of 9.8 and $8.3 \AA$, respectively, with much smaller shoulder values around 4.0 and 5.3 $\AA$. This qualitative trend was supported by calculated pore size distributions based on non-local density functional theory (NLDFT) applied to $\mathrm{CO}_{2}$ adsorption at $273 \mathrm{~K}$ which also indicated pores of $<4 \AA$ in the MPDTrip and MPDTMC polyamides (Figure S6a-b). Based on this analysis, MPDTrip cannot be classified as a typical high BET surface area polymer of intrinsic microporosity. However, the sterically contorted Trip building block in MPDTrip induced enhanced free volume with finely tuned, slightly increased submicropore size (3.9 $\AA)$ compared to its more conventional counterpart MPDTMC (3.6 ̊), resulting in significantly boosted liquid permeances while maintaining excellent solute rejections, as discussed below. Thermogravimetric analysis of MPDTrip powder (Figure S8) demonstrated excellent thermal 


\section{WILEY-VCH}

stability up to $300{ }^{\circ} \mathrm{C}$, comparable to aromatic MPDTMC polyamide, implying potential to develop high-performance TFC membranes with chemical and thermal stability for hightemperature applications.

Table S1 summarizes the conditions for membrane preparation and their physical properties discussed in this work. All membrane types were characterized by FTIR spectroscopy (Figure S9) to confirm the formation of polyamide layers.
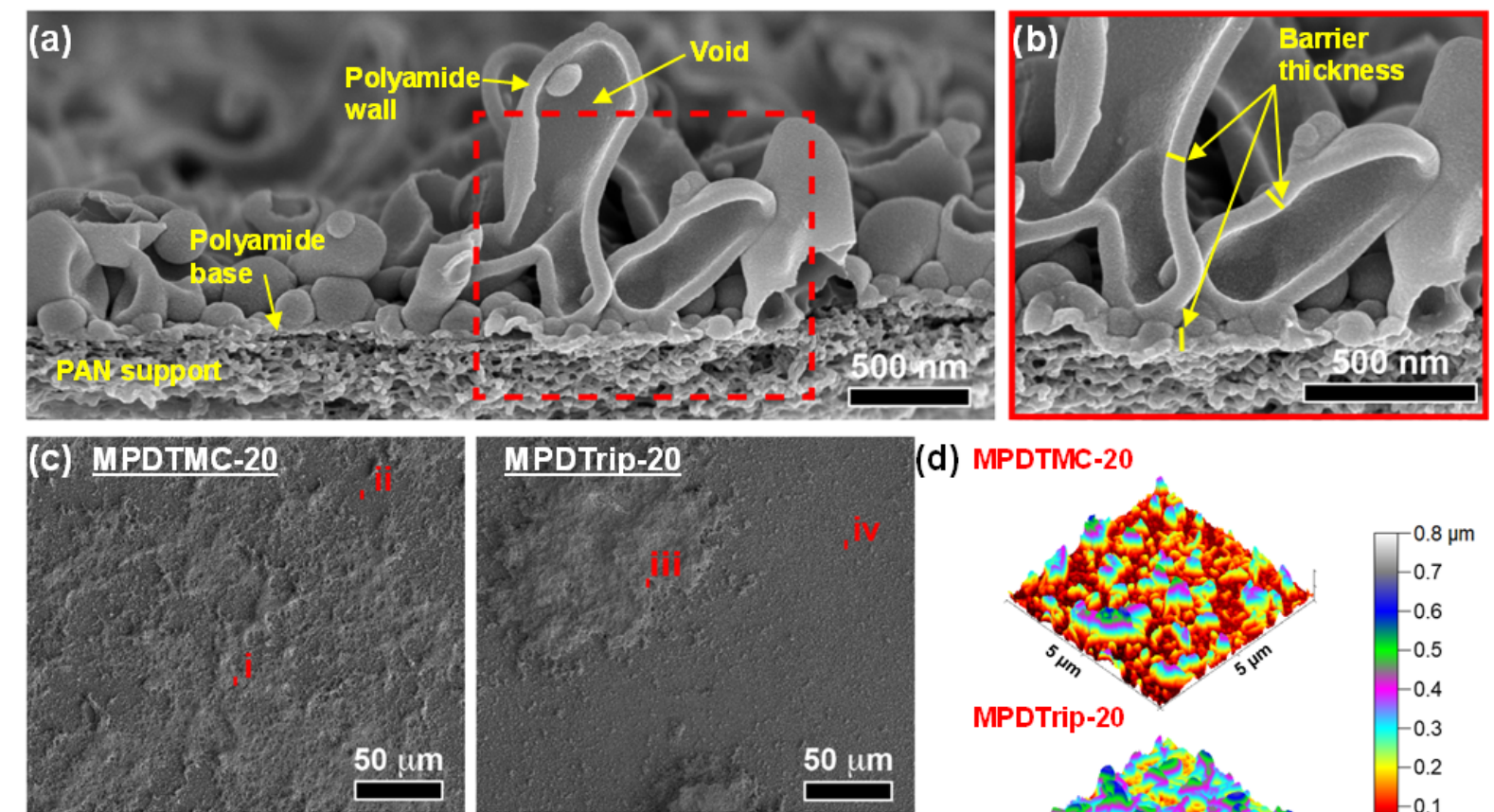

(d) MPDTMC-20
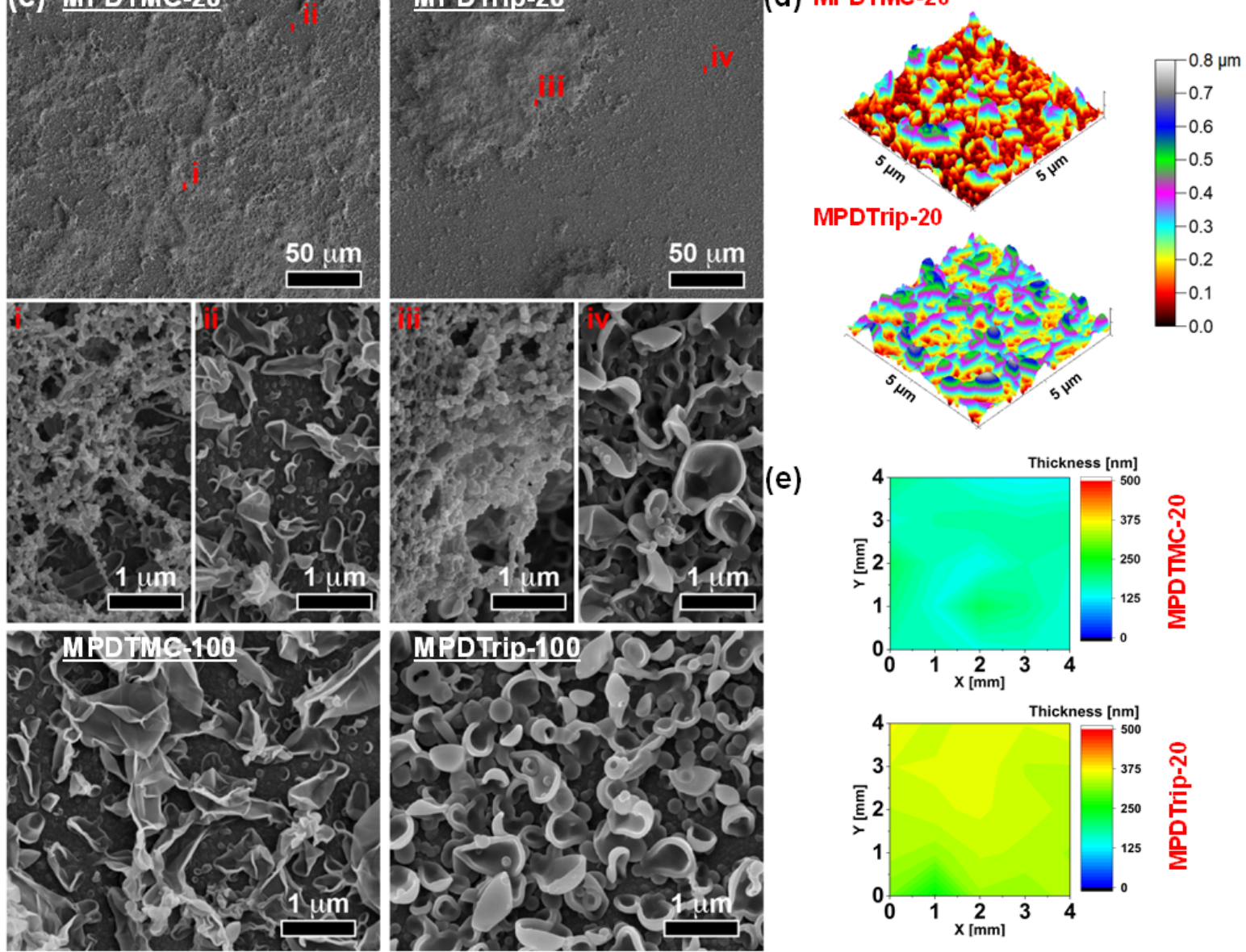

Figure 2. Imaging of interfacially polymerized TFC membranes. (a) Cross-section SEM image of a defect-free MPDTrip-100 membrane highlighting structural features, (b) high magnification SEM image of MPDTrip-100 TFC emphasizing the selective layer and support/selective layer interface, (c) SEM top surface images of the TFCs. Samples produced 


\section{WILEY-VCH}

using an organic solution temperature of $20^{\circ} \mathrm{C}$ show two distinct top layer structures as highlighted by insets i-iv, (d) 3D visualizations of the MPDTMC-20 and MPDTrip-20 surfaces using AFM, (e) Ellipsometry images highlighting the variance in surface morphology over larger sample areas, i.e., 4x4 mm for MPDTMC-20 and MPDTrip-20.

Figure 2a and Figure S11 show a similar ridge-and-valley structure for the MPDTrip TFCs as commonly observed for conventional MPDTMC network polymers. ${ }^{[39-41]}$ Figure 2 b displays the loose, highly heterogeneous structure of the top surface of the TFC membranes that is composed of large voids trapped within thin polyamide layers. ${ }^{[42]}$ Membranes fabricated at $20{ }^{\circ} \mathrm{C}$ exhibit partial surface coverage (based on multiple sample images estimated to be less than $5 \%$ of the total surface area) by powder-like network polymer features on the top of the ridge-and-valley assemblies (Figure 2c sections i-iv), which have been previously observed for membranes made by the IP process and were postulated to have negligible effects on transport properties. ${ }^{[43-47]}$ On both the micron- (AFM characterization, Figure 2d, and Figure S12-13) and millimeter scales (via ellipsometry, Figures 2e and S14) MPDTrip-20 displayed higher surface roughness compared to MPDTMC-20 (Table S2). Thickness estimations (Table S3) using ellipsometry indicated on average thicker MPDTrip layers compared to MPDTMC membranes.

Separation of high value solutes and environmentally harmful compounds dissolved in organic media by organic solvent nanofiltration (OSN) is a membrane process with significant industrial potential. However, currently very few membranes are suitable for OSN application due to insufficient solvent permeance and/or solute rejection. ${ }^{[48,49]}$ In our study, the substitution of TMC with the bulkier, more sterically hindered Trip monomer significantly enhanced water and organic solvent permeance, as shown in Table S6 (in good qualitative agreement with enhanced submicroporous free volume described above). The replacement of TMC with Trip boosted the water permeance from 3.4 to $9.2 \mathrm{LMH} / \mathrm{bar}(\sim 170 \%$ increase). In a series of aliphatic alcohols, methanol permeance exhibited an increase of $80 \%$ from 4.8 to $9.1 \mathrm{LMH} / \mathrm{bar}$ and more significant permeance enhancements were observed for ethanol from 1.0 to $2.4 \mathrm{LMH} / \mathrm{bar}$ 


\section{WILEY-VCH}

( $\sim 140 \%$ increase), and isopropanol permeance even soared from 0.05 to $0.36 \mathrm{LMH} / \mathrm{bar}(\sim 600 \%$ increase). Meanwhile, polar aprotic solvents exhibited even larger permeance enhancements of $\sim 1700 \%$ for acetone and methyl ethyl ketone (MEK), and $2900 \%$ for tetrahydrofuran (THF) in MPDTrip TFCs compared to their MPDTMC counterparts (Table S6).

(a)

(c)
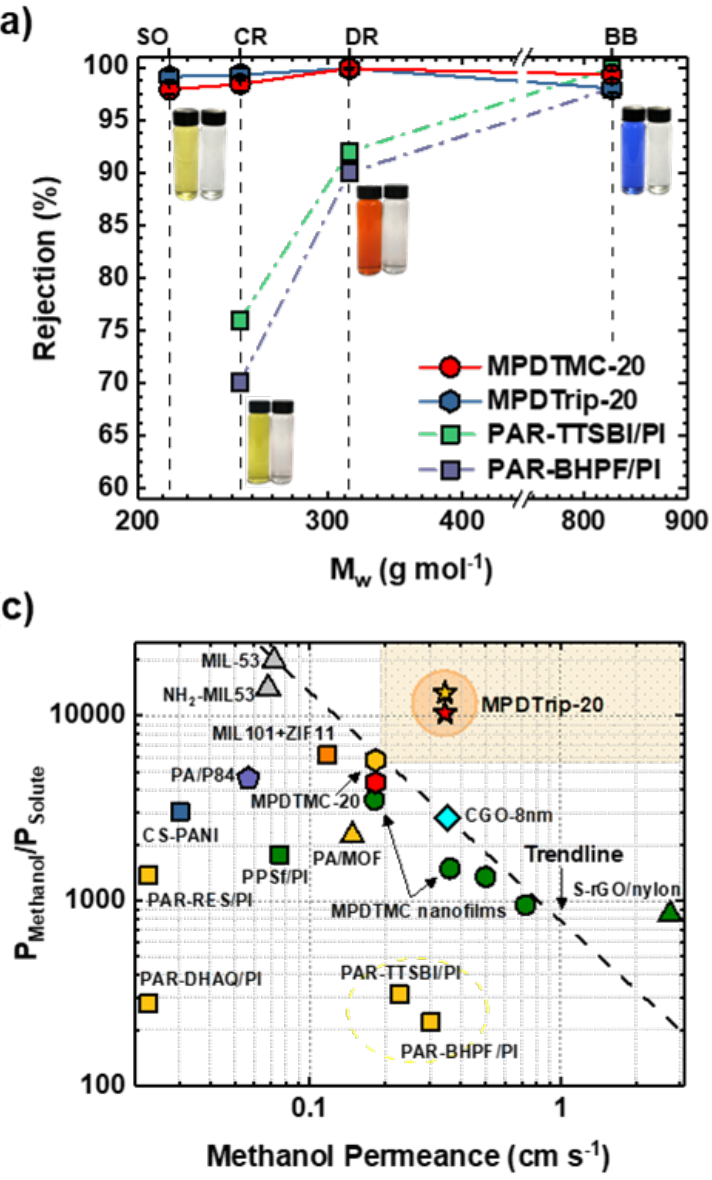

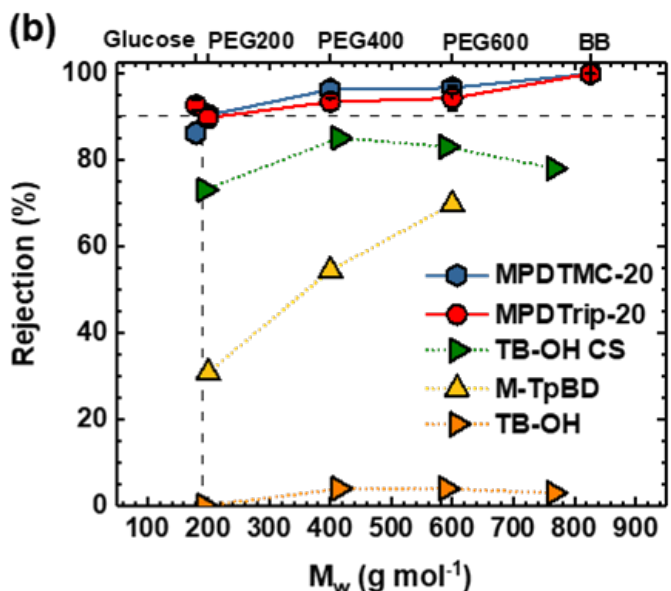

(d)

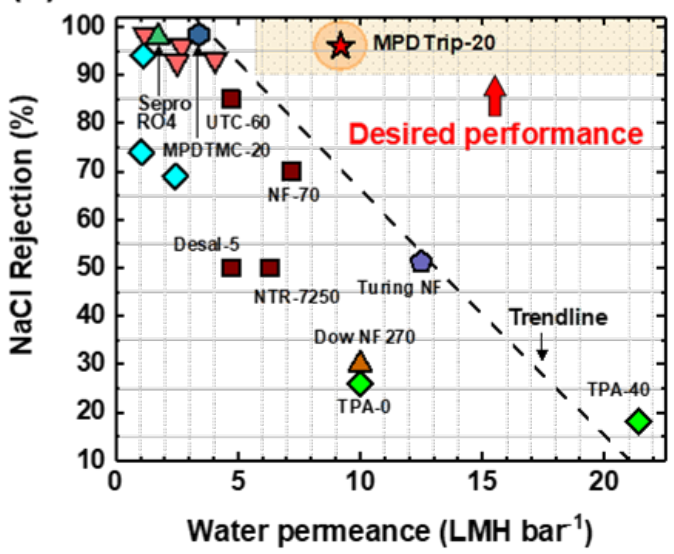

Figure 3. Liquid separation properties of the TFC membranes. (a) Rejection of various dyes through fabricated TFCs in methanol; $\mathrm{SO}=$ Sudan Orange $\left(\mathrm{Mw}=216 \mathrm{~g} \mathrm{~mol}^{-1}\right) ; \mathrm{CR}=$ Chrysoidine $\mathrm{G}\left(\mathrm{Mw}=249 \mathrm{~g} \mathrm{~mol}^{-1}\right)$; $\mathrm{DR}=$ Disperse Red $\left(\mathrm{Mw}=314 \mathrm{~g} \mathrm{~mol}^{-1}\right) ; \mathrm{BB}=\mathrm{Brilliant}$ Blue $\mathrm{R}\left(\mathrm{Mw}=826 \mathrm{~g} \mathrm{~mol}^{-1}\right)$. Comparitive data for microporous TFCs (PAR-TTSBI/PI and PARBHPF/PI) obtained from Jimenez-Solomon et al. ${ }^{[27]}$, (b) rejection of selected solutes through fabricated TFCs in water. Comparitive data for microporous TFCs obtained from Kandambeth et al. ${ }^{[50]}(\mathrm{M}-\mathrm{TpBD})$ and Agarwal et al. ${ }^{[51]}$ (TB-OH and TB-OH CS), (c) permeance of methanol vs. selectivity for small solutes $\left(210-320 \mathrm{~g} \mathrm{~mol}^{-1}\right)$ for state-of-the-art TFCs. Comparative data were obtained from the literature ${ }^{[27,52-59]}$ with details shown in Table S12, (d) sodium chloride rejection comparison of the MPDTrip-20 TFC membrane fabricated in this study with state-ofthe-art desalination membranes. Comparative data were obtained from the literature ${ }^{[33,60-65]}$ with details listed in Table S14. 


\section{WILEY-VCH}

At a high relative pressure of 0.95 , the water vapor sorption of bulk powders revealed $30 \%$ increased water uptake (from 13 to $17.4 \mathrm{mmol} \mathrm{g}^{-1}$ ) in the MPDTrip polymer compared to MPDTMC, as shown in Figures S17-S18. Meanwhile, MPDTrip methanol uptake decreased by $25 \%\left(7.7\right.$ to $\left.5.8 \mathrm{mmol} \mathrm{g}^{-1}\right)$ compared to MPDTMC. Hence, the $170 \%$ and $80 \%$ increases for MPDTrip-20 in water and methanol permeance, respectively, were most likely due to enhanced diffusivity of the solvents through the higher free volume MPDTrip membranes.

Both in-house fabricated TFCs demonstrated excellent rejection for small dyes in methanol (as shown in Figure 3a) with MWCOs of $200 \mathrm{~g} \mathrm{~mol}^{-1}$. Substitution of TMC with Trip improved methanol permeance while maintaining high rejection for even the small Sudan Orange G dye $\left(\mathrm{SO}-\mathrm{Mw}=216 \mathrm{~g} \mathrm{~mol}^{-1}\right)-$ for example, MPDTrip-20 showed $\sim 80 \%$ increased methanol permeance from 4.8 to $8.7 \mathrm{LMH} \mathrm{bar}^{-1}$ with a high rejection of $99.1 \pm 0.6 \%$. Interestingly, the average rejection of MPDTrip-20 for the largest dye in this series, Brilliant Blue $\mathrm{R}(\mathrm{Mw}=826$ $\left.\mathrm{g} \mathrm{mol}^{-1}\right)$, was slightly lower $(98 \pm 1.3 \%)$, which could be due to adsorption of some dye on the membrane surface (Table S7).

The high dye rejection was sustained when methanol was substituted with ethanol or isopropanol as the solvent phase (Table S8-S10). This can potentially be explained by the increased proportion of interconnected size-selective submicroporous regions in the MPDTrip polymer (as observed with NLDFT and XRD pore size characterization) which can be finely tuned to improve solvent permeance while maintaining size selectivity. These results are particularly interesting compared to state-of-the-art polyarylate microporous TFC membranes previously reported which exhibit low rejection $(<<90 \%)$ for solutes $<300 \mathrm{~g} \mathrm{~mol}^{-1}{ }^{[27]}$ An identical high rejection trend was maintained when solute rejection was measured in aqueous systems (Figure 3b). Both in-house membranes exhibited excellent and comparable solute rejections (MWCO 200 $\mathrm{g} \mathrm{mol}^{-1}$ ) with MPDTrip TFCs demonstrating 180\% improved water permeance compared to MPDTMC. Comparably, previous attempts to analyze the feasbility of microporous materials for aqueous separations demonstrated improved permeance but coupled 


\section{WILEY-VCH}

with significant losses in solute rejection and MWCO as shown for Tröger's base PIMs (TB$\mathrm{OH}$ and TB-OH CS) and covalent organic-framework-based membranes (M-TpBD) in Figure 3b. ${ }^{[50,51]}$ The ability to couple high permeance with high rejection truly differentiates the MPDTrip TFCs in this study to previous approaches which resulted in permeance gains with significant rejection losses for liquid separations ${ }^{[27,50-59]}$ and fills a consistently reiterated need in the chemical industry. ${ }^{[48,49,66,67]}$

Filtration performance of MPDTrip-20 TFCs with methanol was further evaluated via the permeance/selectivity trade-off (displayed in Figure 3c) in comparison to state-of-the-art TFC membranes. Clearly, MPDTrip polyamide membranes significantly exceeded the selectivity performance of recently reported ultrathin MPDTMC nanofilms $(<10 \mathrm{~nm})$ synthesized on cadmium hydroxide nanostrands supports while matching their permeance. ${ }^{[52]}$ Furthermore, MPDTrip-20 TFC showed enhanced permselectivity compared to MOF-integrated TFC polyamides as well as previously fabricated high-free-volume thin-film polyarylates (intended for organic nanofiltration applications) that currently remain the most successful efforts to introduce kinked building blocks in the interfacial polymerization membrane fabrication process. ${ }^{[27,68]}$

MPDTrip membranes also displayed excellent stability and separation performance in water/salt separations, specifically for brackish water purification (Figure 3d). MPDTrip-20 showed high sodium chloride rejection of $\sim 96 \%$ with water permeance of $9.2 \mathrm{LMH} / \mathrm{bar}$. In comparison, commercial Dow Filmtec NF270 nanofiltration and recently fabricated Turingstructured polyamide membranes exhibit similar water permeance of $\sim 10$ and $\sim 12.5 \mathrm{LMH} / \mathrm{bar}$, respectively, but with very low sodium chloride rejections of $\sim 30$ and $\sim 50 \%$, respectively (Figure 3d). ${ }^{[62,65]}$ As expected for a more size-selective defect-free membrane, MPDTrip demonstrated exceptional permeance/rejection performance for a series of divalent salts, as shown in Table S13. Long-term continuous performance over a period of $100 \mathrm{~h}$ of MPDTrip 


\section{WILEY-VCH}

demonstrated excellent stability of water permeance $\left(\sim 10 \mathrm{LMH} \mathrm{bar}^{-1}\right)$ and $\mathrm{NaCl}$ rejection of 96\% (Figure S23).

In preliminary studies for potential gas separation applications, MPDTrip-100 TFCs demonstrated 4-fold increase in $\mathrm{H}_{2}$ permeance (56 vs. $14 \mathrm{GPU}$ ) compared to the tighter MPDTMC-100 membrane coupled with a drop in $\mathrm{H}_{2} / \mathrm{CO}_{2}$ selectivity from $\sim 26$ to 9 (Table S15S16). However, the MPDTrip-100 TFC membrane displayed about 2-3 times higher $\mathrm{H}_{2}$ permeance with equivalent selectivity of $\sim 9$ compard to the best previously reported state-ofthe-art hydrogen/carbon dioxide separation membranes (Table S17). ${ }^{[28,69-72]}$ The enhanced performance of crosslinked submicroporous MPDTrip TFC membranes demonstrates the extraordinary potential of applying a triptycene building block combined with interfacial polymerization to fabricate highly selective and permeable polyamide TFC membranes across water, organic solvent, and gas systems.

\section{Experimental Section}

Membrane Fabrication: The synthesis and characterization of the novel triptycene-1,3,6,8tetraacyl chloride (Trip) is described in detail in Section 1.5 of the Supporting Information. Membranes were fabricated using interfacial polymerization with methods similar to ones mentioned elsewhere. ${ }^{[23,61]}$ Sepro PAN-350 coupons $(11.5 \times 15.5 \mathrm{~cm})$ were first immersed in tap water for $24 \mathrm{~h}$ followed by $1 \mathrm{~h}$ in deionized (DI) water. Thereafter, $2 \mathrm{wt}$ vol $\%^{-1}$ of MPD was

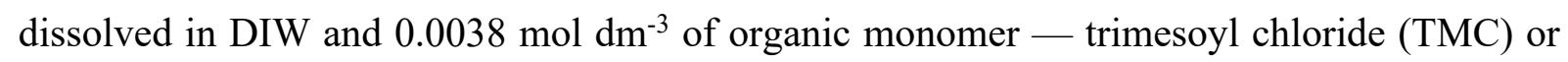
triptycene-1,3,6,8-tetraacetyl chloride (Trip) —was dissolved in toluene. The organic solution was heated at the required temperature for $30 \mathrm{~min}$, i.e., $20^{\circ} \mathrm{C}$ for liquid separation membranes or $100{ }^{\circ} \mathrm{C}$ for gas separation membranes. The porous support was immersed in the aqueous phase for $5 \mathrm{~min}$, followed by passing through a rubber roller. It was then fixed in a Teflon frame, and the organic phase was poured over the top surface. The reaction time was set at $300 \mathrm{~s}$, and then the sample was washed with toluene and iso-propanol three times, respectively. Finally, 


\section{WILEY-VCH}

the membrane was dried at room temperature for $48 \mathrm{~h}$ before testing. The sample designation is defined by i) monomer type, e.g., MPDTMC or MPDTrip, and ii) temperature of the organic phase, e.g. "-20" and "-100" for 20 and $100{ }^{\circ} \mathrm{C}$, respectively. Data from at least three samples were collected for all liquid and gas permeation tests.

Permeation experiments: The permeation properties of pure solvent and methanol/dye as well as aqueous PEG feeds (Section 1.2 Supporting Information) were determined using a dead-end filtration system operated at a feed pressure of 15.5 bar. Brackish water flux and salt rejections were measured using a cross-flow system operated at 15.5 bar. The pure-gas permeation properties of the membranes were carried out with a constant pressure/variable volume set-up at a feed and permeate pressure of 7.9 bar and 1 bar, respectively. All experiments were performed at $23{ }^{\circ} \mathrm{C}$.

\section{Supporting Information}

Supporting Information is available from the Wiley Online Library or from the author.

Conflict of Interest: The authors have no financial/commercial Conflict of Interest.

\section{Acknowledgements}

The research reported in this publication was supported by funding (BAS/1/1323-01-01) from King Abdullah University of Science and Technology (KAUST). The authors would like to thank Dr. Tiara Puspasari for her help with collecting electrokinetic data.

Received: ((will be filled in by the editorial staff))

Revised: ((will be filled in by the editorial staff)) Published online: ((will be filled in by the editorial staff)) 


\section{WILEY-VCH}

\section{References}

[1] D. S. Sholl, R. P. Lively, Nature 2016, 532, 435.

[2] W. J. Koros, R. P. Lively, AIChE J. 2012, 58, 2624.

[3] K. Sutherland, Profile of the International Membrane Industry, Elsevier Science Ltd, Oxford, 2003.

[4] B. D. Zdravkov, J. J. Čermák, M. Šefara, J. Janků, Open Chem. 2007, 5, 385.

[5] J. E. Cadotte, R. J. Petersen, R. E. Larson, E. E. Erickson, Desalination 1980, 32, 25.

[6] R. J. Petersen, J. Membr. Sci. 1993, 83, 81.

[7] K. P. Lee, T. C. Arnot, D. Mattia, J. Membr. Sci. 2011, 370, 1.

[8] M. J. T. Raaijmakers, N. E. Benes, Prog. Polym. Sci. 2016, 63, 86.

[9] P. Vandezande, L. E. M. Gevers, I. F. J. Vankelecom, Chem. Soc. Rev. 2008, 37, 365.

[10] S. Hermans, E. Dom, H. Mariën, G. Koeckelberghs, I. F. J. Vankelecom, J. Membr. Sci. $\mathbf{2 0 1 5}, 476,356$.

[11] B. Van der Bruggen, J. C. Jansen, A. Figoli, J. Geens, K. Boussu, E. Drioli, J. Phys. Chem. B 2006, 110, 13799.

[12] P. M. Budd, N. B. McKeown, D. Fritsch, J. Mater. Chem. 2005, 15, 1977.

[13] P. M. Budd, K. J. Msayib, C. E. Tattershall, B. S. Ghanem, K. J. Reynolds, N. B. McKeown, D. Fritsch, J. Membr. Sci. 2005, 251, 263.

[14] R. Swaidan, B. Ghanem, I. Pinnau, ACS Macro Lett. 2015, 4, 947.

[15] Y. Wang, X. Ma, B. S. Ghanem, F. Alghunaimi, I. Pinnau, Y. Han, Mater. Today Nano 2018, 3, 69 .

[16] B. S. Ghanem, M. Hashem, K. D. M. Harris, K. J. Msayib, M. Xu, P. M. Budd, N. Chaukura, D. Book, S. Tedds, A. Walton, N. B. McKeown, Macromolecules 2010, 43, 5287.

[17] P. M. Budd, N. B. McKeown, B. S. Ghanem, K. J. Msayib, D. Fritsch, L. Starannikova, N. Belov, O. Sanfirova, Y. Yampolskii, V. Shantarovich, J. Membr. Sci. 2008, 325, 851. 


\section{WILEY-VCH}

[18] B. S. Ghanem, N. B. McKeown, P. M. Budd, J. D. Selbie, D. Fritsch, Adv. Mater. 2008, $20,2766$.

[19] F. Alghunaimi, B. Ghanem, N. Alaslai, R. Swaidan, E. Litwiller, I. Pinnau, J. Membr. Sci. 2015, 490, 321.

[20] M. Carta, R. Malpass-Evans, M. Croad, Y. Rogan, J. C. Jansen, P. Bernardo, F. Bazzarelli, N. B. McKeown, Science 2013, 339, 303.

[21] Y. Rogan, R. Malpass-Evans, M. Carta, M. Lee, J. C. Jansen, P. Bernardo, G. Clarizia, E. Tocci, K. Friess, M. Lanč, N. B. McKeown, J. Mater. Chem. A 2014, 2, 4874.

[22] M. Cook, P. R. J. Gaffney, L. G. Peeva, A. G. Livingston, J. Membr. Sci. 2018, 558, 52.

[23] Z. Ali, F. Pacheco, E. Litwiller, Y. Wang, Y. Han, I. Pinnau, J. Mater. Chem. A 2017, 6, 30.

[24] J. Lee, A. Hill, S. Kentish, Sep. Purif. Technol. 2013, 104, 276.

[25] M. Shi, Z. Wang, S. Zhao, J. Wang, P. Zhang, X. Cao, J. Membr. Sci. 2018, 555, 157.

[26] M. Shi, W. Yan, Y. Zhou, Z. Wang, L. Liu, S. Zhao, Y. Ji, J. Wang, C. Gao, P. Zhang, X. Cao, J. Membr. Sci. 2020, 595, 117474.

[27] M. F. Jimenez-Solomon, Q. Song, K. E. Jelfs, M. Munoz-Ibanez, A. G. Livingston, Nat. Mater. 2016, 15, 760.

[28] B. S. Ghanem, R. Swaidan, X. Ma, E. Litwiller, I. Pinnau, Adv. Mater. 2014, 26, 6696.

[29] N. T. Tsui, A. J. Paraskos, L. Torun, T. M. Swager, E. L. Thomas, Macromolecules 2006, 39,3350 .

[30] R. Bera, S. Mondal, N. Das, Polymer 2017, 111, 275.

[31] G. Genduso, B. S. Ghanem, Y. Wang, I. Pinnau, Polymers 2019, 11, 361.

[32] M. Carta, M. Croad, R. Malpass-Evans, J. C. Jansen, P. Bernardo, G. Clarizia, K. Friess, M. Lanč, N. B. McKeown, Adv. Mater. 2014, 26, 3526.

[33] L. Ren, J. Chen, C. Wang, Q. Lu, J. Han, H. Wu, J. Taiwan Inst. Chem. Eng. 2019, 101, 119. 


\section{WILEY-VCH}

[34] H. Zhou, F. Tao, Q. Liu, C. Zong, W. Yang, X. Cao, W. Jin, N. Xu, Angew. Chemie Int. Ed. 2017, 56, 5755.

[35] H. A. Patel, C. T. Yavuz, Chem. Comm. 2012, 48, 9989.

[36] R. Swaidan, B. S. Ghanem, E. Litwiller, I. Pinnau, J. Membr. Sci. 2014, 457, 95.

[37] X. Ma, Y. Wang, K. Yao, Z. Ali, Y. Han, I. Pinnau, ACS Omega 2018, 3, 15966.

[38] R. Swaidan, B. Ghanem, E. Litwiller, I. Pinnau, J. Membr. Sci. 2015, 475, 571.

[39] F. A. Pacheco, I. Pinnau, M. Reinhard, J. O. Leckie, J. Membr. Sci. 2010, 358, 51.

[40] C. Y. Tang, Y. N. Kwon, J. O. Leckie, J. Membr. Sci. 2007, 287, 146.

[41] J. Duan, E. Litwiller, I. Pinnau, J. Membr. Sci. 2015, 473, 157.

[42] F. Pacheco, R. Sougrat, M. Reinhard, J. O. Leckie, I. Pinnau, J. Membr. Sci. 2016, 501, 33.

[43] S. J. Park, S. J. Kwon, H. E. Kwon, M. G. Shin, S. H. Park, H. Park, Y. I. Park, S. E. Nam, J. H. Lee, Polymer 2018, 144, 159.

[44] T. Kamada, T. Ohara, T. Shintani, T. Tsuru, J. Membr. Sci. 2014, 467, 303.

[45] T. Kamada, T. Ohara, T. Shintani, T. Tsuru, J. Membr. Sci. 2014, 453, 489.

[46] C. Kong, M. Kanezashi, T. Yamomoto, T. Shintani, T. Tsuru, J. Membr. Sci. 2010, 362, 76.

[47] C. Kong, T. Shintani, T. Kamada, V. Freger, T. Tsuru, J. Membr. Sci. 2011, 384, 10.

[48] P. Marchetti, M. F. Jimenez Solomon, G. Szekely, A. G. Livingston, Chem. Rev. 2014, $114,10735$.

[49] P. Marchetti, L. Peeva, A. Livingston, Annu. Rev. Chem. Biomol. Eng. 2017, 8, 473.

[50] S. Kandambeth, B. P. Biswal, H. D. Chaudhari, K. C. Rout, S. Kunjattu H., S. Mitra, S. Karak, A. Das, R. Mukherjee, U. K. Kharul, R. Banerjee, Adv. Mater. 2017, 29, 1603945.

[51] P. Agarwal, R. E. Hefner, S. Ge, I. Tomlinson, Y. Rao, T. Dikic, J. Membr. Sci. 2020, $595,117501$.

[52] S. Karan, Z. Jiang, A. G. Livingston, Science 2015, 348, 1347. 


\section{WILEY-VCH}

[53] S. Sorribas, P. Gorgojo, C. Téllez, J. Coronas, A. G. Livingston, J. Am. Chem. Soc. 2013, $135,15201$.

[54] Q. Yang, Y. Su, C. Chi, C. T. Cherian, K. Huang, V. G. Kravets, F. C. Wang, J. C. Zhang, A. Pratt, A. N. Grigorenko, F. Guinea, A. K. Geim, R. R. Nair, Nat. Mater. 2017, 16, 1198.

[55] X. X. Loh, M. Sairam, A. Bismarck, J. H. G. Steinke, A. G. Livingston, K. Li, J. Membr. Sci. 2009, 326, 635 .

[56] J. C. Jansen, S. Darvishmanesh, F. Tasselli, F. Bazzarelli, P. Bernardo, E. Tocci, K. Friess, A. Randova, E. Drioli, B. Van der Bruggen, J. Membr. Sci. 2013, 447, 107.

[57] M. F. Jimenez-Solomon, Y. Bhole, A. G. Livingston, J. Membr. Sci. 2013, 434, 193.

[58] C. Echaide-Górriz, M. Navarro, C. Téllez, J. Coronas, Dalt. Trans. 2017, 46, 6244.

[59] L. Huang, J. Chen, T. Gao, M. Zhang, Y. Li, L. Dai, L. Qu, G. Shi, Adv. Mater. 2016, 28,8669 .

[60] M. Dalwani, N. E. Benes, G. Bargeman, D. Stamatialis, M. Wessling, J. Membr. Sci. 2011, 372, 228.

[61] Z. Ali, Y. Al Sunbul, F. Pacheco, W. Ogieglo, Y. Wang, G. Genduso, I. Pinnau, J. Membr. Sci. 2019, 579, 85 .

[62] Z. Tan, S. Chen, X. Peng, L. Zhang, C. Gao, Science 2018, 360, 518.

[63] Z. Jiang, S. Karan, A. G. Livingston, Adv. Mater. 2018, 30, 1870107.

[64] F. Foglia, S. Karan, M. Nania, Z. Jiang, A. E. Porter, R. Barker, A. G. Livingston, J. T. Cabral, Adv. Funct. Mater. 2017, 27, 1701738.

[65] L. Meihong, Y. Sanchuan, Z. Yong, G. Congjie, J. Membr. Sci. 2008, 310, 289.

[66] J. R. Werber, A. Deshmukh, M. Elimelech, Environ. Sci. Technol. Lett. 2016, 3, 112.

[67] H. B. Park, J. Kamcev, L. M. Robeson, M. Elimelech, B. D. Freeman, Science 2017, 356, 1138.

[68] C. Echaide-Górriz, S. Sorribas, C. Téllez, J. Coronas, RSC Adv. 2016, 6, 90417. 


\section{WILEY-VCH}

[69] United States Department of Energy, Advanced Carbon Dioxide Capture R\&D Program: Technology Update: Pre-Combustion Membranes, Pittsburgh, 2013.

[70] J. Sánchez-Laínez, L. Paseta, M. Navarro, B. Zornoza, C. Téllez, J. Coronas, Adv. Mater. Int. 2018, 5, 1800647.

[71] L. F. Villalobos, R. Hilke, F. H. Akhtar, K. V. Peinemann, Adv. Energy Mater. 2018, 8, 1701567.

[72] W. F. Yong, F. Y. Li, T. S. Chung, Y. W. Tong, J. Membr. Sci. 2014, 462, 119. 


\section{WILEY-VCH}

\section{Table of Contents}

\section{ToC text}

Novel pressure-driven thin-film composite membranes containing entrapped structural submicroporosity (pore size $<4 \AA$ ) exhibit superb performance for removal of small solutes from aqueous or organic solutions. The membranes potentially lower the energy burden and improve the environmental sustainability of chemical separations that are currently based on thermal principles and account for $\sim 10-15 \%$ of the world's total energy consumption.

\section{ToC figure}

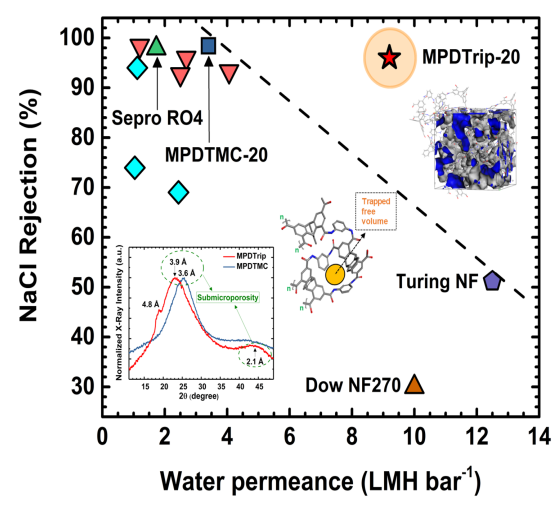

\section{ToC keyword}

Submicroporous thin-film composite membrane 


\section{WILEY-VCH}

Copyright WILEY-VCH Verlag GmbH \& Co. KGaA, 69469 Weinheim, Germany, 2016. 